Tropical Journal of Pharmaceutical Research April 2021; 20 (4): 833-838

ISSN: $1596-5996$ (print); 1596-9827 (electronic)

(C) Pharmacotherapy Group, Faculty of Pharmacy, University of Benin, Benin City, 300001 Nigeria.

\title{
Antioxidant and anti-inflammatory activities of Oroxylum indicum Kurz (L.) fruit extract in lipopolysaccharide- stimulated BV2 microglial cells
}

\author{
Nootchanat Mairuae ${ }^{1 *}$, Poonlarp Cheepsunthorn ${ }^{2}$, Benjaporn Buranrat ${ }^{1}$ \\ ${ }^{1}$ Faculty of Medicine, Mahasarakham University, Maha Sarakham 44000, '2Faculty of Medicine, Chulalongkorn University, \\ Bangkok 10330, Thailand
}

*For correspondence: Email: mairuae.n@gmail.com, nootchanat.m@msu.ac.th; Tel: 6643-021021-992; Fax: 6643-021021

Sent for review: 11 September 2020

Revised accepted: 15 March 2021

\begin{abstract}
Purpose: To investigate the anti-inflammatory effects and antioxidant activity of Oroxylum indicum (L.) Kurz fruit extract in lipopolysaccharide (LPS)-stimulated BV2 microglia.

Methods: BV2 cells were treated with LPS for $24 \mathrm{~h}$ in the presence or absence of 0 . indicum fruit extract. Then, nitric oxide (NO), reactive oxygen species (ROS) and interleukin 6 (IL-16) levels were measured using Griess reagent assay, CM-H2DCFDA and enzyme-linked immunosorbent (ELISA) assays, respectively. The in vitro antioxidant property of the extract was also investigated by 1,1diphenyl-2-picrylhydrazyl (DPPH) and 2,2'-azino-bis-3-ethylbenzthiazoline-6-sulphonic acid (ABTS) assays.

Results: Levels of IL-6, NO, and ROS in LPS-treated BV2 cells were significantly higher than those in control $(p<0.01)$. However, exposure of LPS-treated BV2 cells to O. indicum extract led to a marked decrease in the levels of these parameters, when compared to the untreated cells $(p<0.01)$. Results from DPPH and ABTS assays showed that the $O$. indicum extract exhibited good antioxidant properties, with total flavonoid and total phenolic contents of $115.58 \pm 1.09$ and $131.04 \pm 2.37 \mathrm{mg} / \mathrm{g}$ of dried extract, respectively.

Conclusion: The results demonstrate that $O$. indicum fruit exerts anti-oxidant and anti-inflammatory effects in LPS-stimulated BV2 cells. Thus O. indicum fruit might be beneficial in the development of novel anti-oxidative and anti-neuroinflammatory herbal medicines. However, the mechanisms by which O. indium fruits reduces NO and IL-6 needs to be further investigated.
\end{abstract}

Keywords: BV2 microglia, IL-6, Nitric oxide, Oroxylum indicum, Reactive oxygen species, Antioxidative, Anti-neuroinflammatory

\begin{abstract}
This is an Open Access article that uses a fund-ing model which does not charge readers or their institutions for access and distributed under the terms of the Creative Commons Attribution License (http://creativecommons.org/licenses/by/4.0) and the Budapest Open Access Initiative (http://www.budapestopenaccessinitiative.org/read), which permit unrestricted use, distribution, and reproduction in any medium, provided the original work is properly credited.

Tropical Journal of Pharmaceutical Research is indexed by Science Citation Index (SciSearch), Scopus, International Pharmaceutical Abstract, Chemical Abstracts, Embase, Index Copernicus, EBSCO, African Index Medicus, JournalSeek, Journal Citation Reports/Science Edition, Directory of Open Access Journals (DOAJ), African Journal Online, Bioline International, Open-J-Gate and Pharmacy Abstracts
\end{abstract}

\section{INTRODUCTION}

Neuroinflammation and oxidative stress mediated by activated microglia have been implicated in the onset and the progression of many neurodegenerative diseases [1]. Chronic microglial activation participates in inflammatory response by producing ROS and releasing NO and various pro-inflammatory cytokines including tumor necrosis factor alpha (TNF- $\alpha$ ), interleukin 1 
beta $(\mathrm{IL}-1 \beta)$, and IL-6 $[2,3]$. The overproduction of these agents reduces neuronal population. Therefore, the control of microglial activation is a beneficial approach in the treatment and prevention of neuroinflammation and neurodegenerative disorders.

Oroxylum indicum (L) Kurz, a plant in the Bignoniaceae family is distributed throughout India and South East Asia. This plant has been applied as a traditional herbal medicine for treatment illnesses in China and Japan [4]. The fruits of $O$. indicum are rich in nutrients [4] and they have been used for thousands of years as part of plant-based diet and herbal medicines in several countries, without any known adverse effects [4-6]. Various parts of the plant are sources of several medicinally important compounds. The fruit of $\mathrm{O}$. indicum contain flavonoids such as oroxylin $A$, baicalein, and chrysin, all of which have been reported to have multiple biological effects.

The pharmacological effects of fruit extract of $O$. indicum and compounds isolated from the fruit exhibit hepatoprotective, antidiabetic, antiadipogenesis antioxidant and anti-inflammatory properties [5,7-9]. A previous study demonstrated that $O$. indicum fruit extract protected SH-SY5Y cells against Aß25-35-induced cell injury [10]. Although many medicinal properties of $O$. indicum fruit have been reported, the scientific data on the effect of $O$. indicum fruits extract on microglial activation has not yet been reported.

Therefore, the present study was carried out to determine the anti-inflammatory and antioxidant effects of $O$. indicum fruits extract on BV2 microglial cells stimulated with LPS.

\section{EXPERIMENTAL}

\section{Preparation of 0 . indicum fruit extract}

The fruit extract of 0 . indicum was prepared as described previously $[10,11]$. The fruits were dried, weighed, chopped, and macerated in $95 \%$ (v/v) ethanol, followed by filtration. The ethanol solvent was evaporated from the crude extract obtained, and the residue was lyophilized.

\section{Cell culturing and treatments of murine BV2 cell}

The BV2 cells were obtained from the Department of Neurosurgery, Hershey Medicine Center (Professor James R Connor's laboratory). All reagents for the cell culture were purchased from HyClone (South Logan, UT). The cells were incubated in Dulbecco's adjusted Eagle's medium (DAEM) containing $5 \%$ fetal bovine serum (FBS), at $37{ }^{\circ} \mathrm{C}$ in a $5 \% \mathrm{CO}_{2}$ incubator. To determine the viability of cells, BV-2 cells were seeded in 96-well plates. When cells reached $80 \%$ confluence, the medium in each well was removed, and replaced with new serumfree DAEM containing various concentrations of $O$. indicum fruit extract $(0-50 \mu \mathrm{g} / \mathrm{mL})$ in the presence or absence of LPS.

In order to quantify the levels of NO, IL-6 and ROS, the growth medium was completely removed and replaced with new medium containing LPS, with or without various concentrations of $O$. indicum fruit extract. Cells in serum-free DAEM served as untreated control.

\section{Evaluation of cell viability}

After $24 \mathrm{~h}$ of treatment with $O$. indicum fruit extract at concentrations of $0-50 \mu \mathrm{g} / \mathrm{mL}$, with or without LPS, the incubation medium was discarded, and $0.4 \mathrm{mg} / \mathrm{mL}$ MTT reagent (Sigma Co St. Louis, MO) in serum-free DAEM was added to each well. After incubation for $2 \mathrm{~h}$, the MTT medium was removed, and the purple formazan crystals formed were solubilized in dimethyl sulfoxide (DMSO). The optical density of each well was read at $570 \mathrm{~nm}$ in a plate reader (Spectramax 340 PC).

\section{Measurement of nitric oxide (NO) assay}

To quantify the nitrite accumulation, NO levels in the cell culture supernatants were estimated using Griess reagent (Invitrogen, Carlsbad, CA) as described previously [11]. In this assay, 150 $\mu \mathrm{L}$ of sample was seeded per well in a 96-well plate. Then, $20 \mu \mathrm{L}$ of Griess reagent was added and mixed with $130 \mu \mathrm{L}$ deionized water. Incubation was carried out for $30 \mathrm{~min}$ at room temperature, after which absorbance of each well was read at $540 \mathrm{~nm}$ using a microplate reader (BiO-Tek Instruments Inc., Winooski, VT).

\section{Determination of ROS generation}

The oxidation of 2',7'-dichlorofluorescein diacetate (DCFH-DA) was used to determine intracellular levels of ROS. The cells were cultured with $10 \mu \mathrm{M}$ DCFH-DA for $20 \mathrm{~min}$ at 37 ${ }^{\circ} \mathrm{C}$ in a $5 \% \mathrm{CO}_{2}$ incubator. Then, the cells were treated with a medium containing LPS, in the presence or absence of various concentrations of O. indicum fruit extract for $24 \mathrm{~h}$. Subsequently, fluorescence intensity was measured at excitation and emission wavelengths of $495 \mathrm{~nm}$ and $525 \mathrm{~nm}$, respectively. 


\section{Assay of IL-6}

The IL-6 levels in the culture supernatant were determined using enzyme-linked immunosorbent assay (ELISA) kits (Minneapolis, MN). The IL-6 levels in the supernatant were quantified by measuring absorbance at $450 \mathrm{~nm}$ using Microplate reader (Bi0-Tek Instruments Inc., Winooski, VT). The concentration of IL-6 in each sample was calculated with reference to IL-6 standard curves.

\section{Determination of DPPH and ABTS radical scavenging activity assay}

Total free radical scavenging capacity of $O$. indicum fruit extract was determined with DPPH and ABTS assay according to the method of Yang et al [12,13].

\section{Determination of total flavonoid and total phenol contents}

Total flavonoid and total phenol contents of $O$. indicum fruit extracts were determined as described in a previous study [10].

\section{Statistical analysis}

Data are expressed as mean \pm S.E.M. One-way ANOVA and Bonferroni post-tests were used for analysis of statistical significance of differences amongst multiple groups. Values of $p<0.05$ were taken as indicative of statistical significance of differences.

\section{RESULTS}

Effect of $O$. indicum fruit extract on the viability of BV2 cells

In this study, MTT assay was applied to determine the effect of $O$. indicum fruit extract on the viability of BV2 cells. The results demonstrated that $\mathrm{O}$. indicum fruit extract at concentrations up to $50 \mu \mathrm{g} / \mathrm{mL}$ exhibited no toxicity against BV2 cells (Figure 1). Thus, 0. indicum fruit extract was used at concentrations of $12.5,25$, and $50 \mu \mathrm{g} / \mathrm{mL}$ in the subsequent studies.

\section{Effect of $O$. indicum fruit extract on LPS- induced NO production}

To investigate the anti-inflammatory effect of $O$. indicum fruit extract, its effect on LPS-induced NO production was examined. The result demonstrates that LPS treatment caused significant increase in NO level in culture media of BV2 microglia, when compared to untreated control. However, treatment with $\mathrm{O}$. indicum led to significant and concentration-dependent decrease in NO levels (Figure 2).

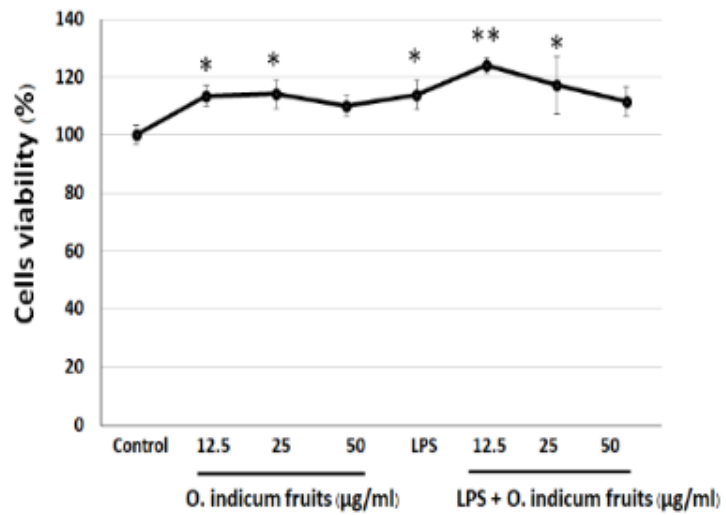

Figure 1: Effect of $O$. indicum fruit extract on BV2 cells viability using MTT assay. BV2 cells were incubated with $O$. indicum fruits extract, alone or with 1 $\mu \mathrm{g} / \mathrm{mL}$ of LPS. Cell viability was determined after $24 \mathrm{~h}$ of treatment. Data from three independent experiments are expressed as percentage of control, and presented as mean $\pm \mathrm{SEM}$; ${ }^{*} p<0.05$, vs. control group; ${ }^{* *} p<0.01$, vs. control group

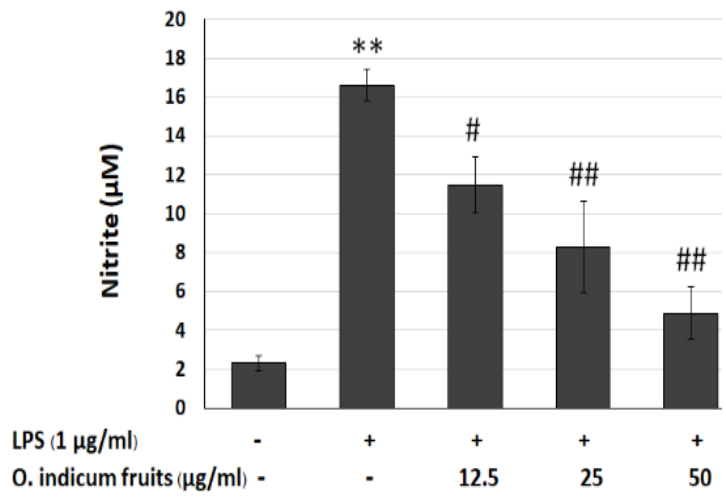

Figure 2: Effect of $\mathrm{O}$. indicum fruits on $\mathrm{NO}$ levels. The BV2 cells were treated as described earlier-on. After $24 \mathrm{~h}$ of treatment, NO level was determined in the culture medium using the Griess assay. Data are presented as mean \pm SEM. Values are mean of three independent experiments. ${ }^{* *} P<0.01$, vs. control group; $\# p<0.05, \# \#<0.01$ vs. LPS-treated group

\section{Effect of $O$. indicum fruit extract on ROS production}

To determine the antioxidant capacity of $O$. indicum fruit extract in activated BV2 cells, the intracellular level of ROS was determined. There was significant increase in level of ROS in LPStreated cells, when compared to control. However, ROS level was significantly decreased in O. indicum extract-treated BV-2 cells (Figure 3). 


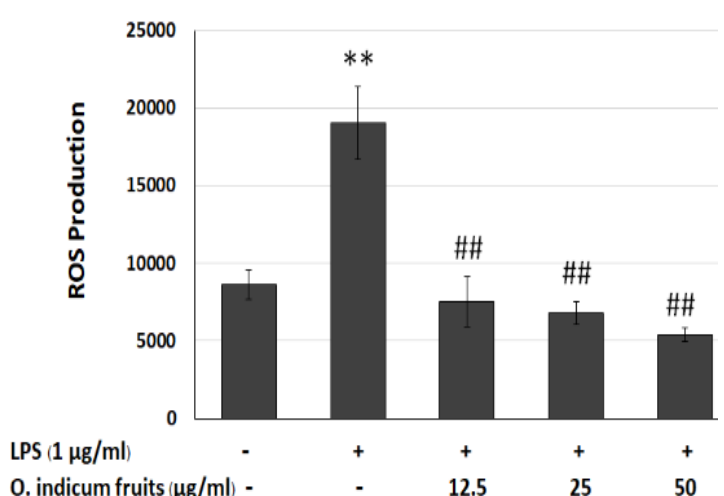

Figure 3: Effect of $O$. indicum fruit extract on ROS production. Cells were treated with LPS $(1 \mu \mathrm{g} / \mathrm{mL})$ in the presence or absence of $O$. indicum fruit extract. Data are presented as mean \pm SEM. Values are mean of three independent experiments. ${ }^{* \star} P<0.01$, vs. control group; \#p< 0.01 vs. LPS-treated group

\section{Effect of 0 . indicum fruit extract on IL-6 levels}

To determine the anti-inflammatory properties of 0 . indicum fruit extract in LPS-activated BV2 microglial cells, IL-6 level was determined using ELISA. As shown in Figure 4, IL-6 level in culture media of BV-2 cells was significantly increased after treatment with LPS, relative to control (untreated cells). However, when the cells were co-treated with LPS and $O$. indicum extract, the level of IL- 6 was significantly decreased in a concentration-dependent manner (Figure 4).

\section{In vitro antioxidant properties of 0 . indicum fruit extract}

The antioxidative potential of $\mathrm{O}$. indicum fruit is shown in Table 1.

Total phenolic and flavonoid contents of $\boldsymbol{O}$. indicum fruit extract

The phenolic content of the extract was $131.04 \pm$ 2.37, while the flavonoid content was $115.58 \pm$ $1.09 \mathrm{mg} / \mathrm{g}$ of dried extract. These results are presented in Table 1.

\section{DISCUSSION}

It has been reported that microglia-mediated neuroinflammation and oxidative stress are linked to neurodegenerative diseases [14]. Therefore, inhibition of microglia activation may have significant impact on the treatment of neurodegenerative diseases.

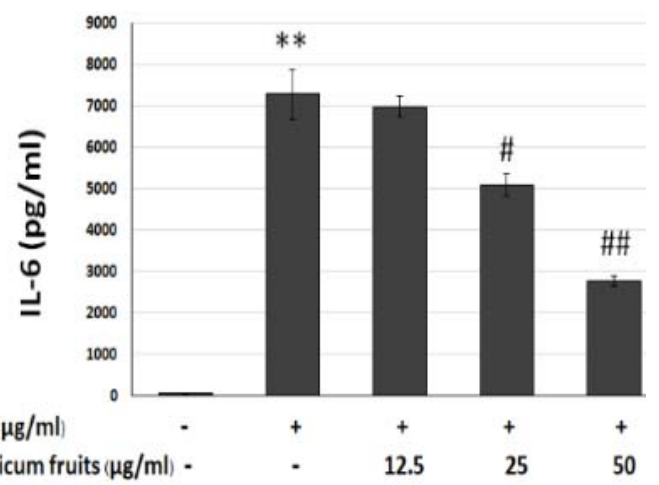

Figure 4: Effect of $O$. indicum fruits on IL-6 levels. Cells were treated with LPS $(1 \mu \mathrm{g} / \mathrm{L})$ in the presence or absence of $O$. indicum fruit extract. The expression of IL-6 was determined after $24 \mathrm{~h}$ of treatment using ELISA kits. Data represent mean \pm SEM values from three independent experiments. ${ }^{* *} P<0.01$ vs control group; \#p < 0.05 vs. LPS-treated group, \#\# < 0.01 vs. LPS-treated group

Using DPPH and ABPS assays, this study showed that $O$. indicum fruit extract has in vitro antioxidant effects. The extract inhibited ROS production in LPS-activated BV2 microglia. Furthermore, it suppressed inflammation by decreasing the levels of $\mathrm{NO}$ and IL-6. Reactive oxygen species (ROS) trigger neuroinflammation by regulating NF-kB transcriptional factors, leading to enhanced expressions of proinflammatory genes. This study has demonstrated that $O$. indicum fruit extract exerted in vitro antioxidant effects by decreasing LPS-induced ROS levels in activated BV-2 microglia. This result is consistent with a previous report which showed that $O$. indicum suppressed LPS-activated ROS in RAW264.7 macrophages, and in vitro antioxidant assay [15]. Therefore, it is possible that $O$. indicum reduced ROS levels due to suppression of oxidation.

In the central nervous system, $\mathrm{NO}$ is the inflammatory mediator derived from activated microglia.

Table 1: In vitro antioxidant property of $O$. indicum fruit extract, and total phenolic and flavonoid contents

DPPH assay (mg Trolox equivalent/g extract)

ABTS assay (mg Trolox equivalent/g extract)

Total phenolic content ${ }^{2}$

Total flavonoid content ${ }^{b}$

${ }^{a} \mathrm{mg}$ gallic acid equivalent/g dry weight; ${ }^{\mathrm{b}} \mathrm{mg}$ rutin equivalent/g dry wt. Values are presented as the mean of three biological replicates
$43.79 \pm 0.35$

$105.64 \pm 0.368$

$131.04 \pm 2.37$

$115.58+1.09$

(10)

Trop J Pharm Res, April 2021; 20(4): 836 
High concentrations of $\mathrm{NO}$ are involved in the onset of multiple sclerosis, AD and PD and other neurodegenerative diseases. It has been established that NO rapidly reacts with superoxide anion to form the highly toxic peroxynitrite anion [16]. Peroxynitrite reacts directly with various biological molecules including lipids, nucleic acids, and proteins [16]. In the present study, Griess reagent was used to assay the secretion of NO by BV-2 cells. The results demonstrated that LPS significantly increased NO production, but this was reversed by $O$. indicum fruit extract, indicating that the extract can mitigate inflammation caused by excessive NO. This result is consistent with a report showing that $O$. indicum fruit suppressed the production of NO in LPS-activated RAW264.7 macrophages [15].

Studies have shown that high IL-6 level is a hallmark of neuroinflammatory diseases [17]. Therefore, the effect of $O$. indicum fruit extract on IL-6 production in activated BV-2 cells was investigated. Treatment with $O$. indicum extract significantly decreased IL-6 levels in LPSactivated BV-2 cells. This result is in line with a previous report showing that $O$. indicum treatment decreased IL-6 production in LPSactivated RAW264.7 macrophages [15]. It has been reported that in 0 . indicum, flavonoid compounds such as apigenin, baicalein, chrysin, luteolin and oroxylin exerted anti-inflammatory effects by modulation of ROS generation and suppression of the proinflammatory cytokines IL6 , TNF- $\alpha$ and IL-1 $\beta$ [18]. In this study, it was demonstrated that total flavonoid and total phenolic contents of $O$. indicum fruit extract were $115.58 \pm 1.09$ and $131.04 \pm 2.37 \mathrm{mg} / \mathrm{g}$ of dried extract, respectively. Thus, a flavonoid-rich extract from $O$. indicum could potentially act as a source of anti-inflammatory compounds.

\section{CONCLUSION}

The results obtained in the present study indicate that $O$. indicum fruit extract mitigates oxidative stress and inflammation by reduction of LPSinduced increases in levels of IL-6, NO, and ROS in BV2 microglial cells. Therefore, the extract has potential for use in development of herbal medicine or food supplement for combating oxidative stress and neuroinflammation.

\section{DECLARATIONS}

\section{Acknowledgement}

This research project was financially supported by Mahasarakham University 2020. Maha Sarakham 44000, Thailand.

\section{Conflict of interest}

No conflict of interest is associated with this work.

\section{Contribution of authors}

We declare that this work was done by the authors named in this article and all liabilities pertaining to claims relating to the content of this article will be borne by the authors.

\section{Open Access}

This is an Open Access article that uses a funding model which does not charge readers or their institutions for access and distributed under the terms of the Creative Commons Attribution License (http://creativecommons.org/licenses/by/ 4.0) and the Budapest Open Access Initiative (http://www.budapestopenaccessinitiative.org/rea d), which permit unrestricted use, distribution, and reproduction in any medium, provided the original work is properly credited.

\section{REFERENCES}

1. Liu B, Hong JS. Role of microglia in inflammationmediated neurodegenerative diseases: mechanisms and strategies for therapeutic intervention. J Pharmacol Exp Ther 2003; 304(7): 1-7.

2. Boje KM, Arora PK. Microglial-produced nitric oxide and reactive nitrogen oxides mediate neuronal cell death. Brain Res 1992; 587(2): 250-256.

3. Chao CC, Hu S, Peterson PK. Glia, cytokines, and neurotoxicity. Crit Rev Neurobiol 1995; 9(2-3): 189-205.

4. Rajeev B, Shaharuddin NA, Kuang YT. A Promising Approach Toward Exploring Nutritional and Functional Qualities of B eko (Oroxylum Indicum L. B enth. Ex Kurz) Pods For Potential Food Applications. Journal of Food Processing and Preservatio 2015; 39(1): 47-55.

5. Siriwatanametanon $N$, Fiebich BL, Efferth T, Prieto JM, Heinrich MN. Traditionally used Thai medicinal plants: in vitro anti-inflammatory, anticancer and antioxidant activities. J Ethnopharmacol 2010; 130(2): 196-207.

6. Dinda, B, SilSarma I, Dinda M, Rudrapaul P. Oroxylum indicum (L.) Kurz, an important Asian traditional medicine: from traditional uses to scientific data for its commercial exploitation. J Ethnopharmacol 2015; 161: 255-278.

7. Singh J, Kakkar P. Modulation of liver function, antioxidant responses, insulin resistance and glucose transport by Oroxylum indicum stem bark in STZ induced diabetic rats. Food Chem Toxicol 2013; 62: 722-731.

8. Hengpratom $T$, Lowe GM, Thumanu K, Suknasang $S$, Tiamyom K, Eumkeb G. Oroxylum indicum (L.) Kurz 
extract inhibits adipogenesis and lipase activity in vitro. BMC Complement Altern Med 2018; 18(1): 177.

9. Dunkhunthod B, Thumanu D, Eumkeb G. Application of FTIR microspectroscopy for monitoring and discrimination of the anti-adipogenesis activity of baicalein in 3T3-L1 adipocytes. Vibrational Spectroscopy 2017; 89: 92-101.

10. Mairuae N, Connor JR, Buranrat B, Lee SY. Oroxylum indicum (L.) extract protects human neuroblastoma SHSY5Y cells against betaamyloid-induced cell injury. Mol Med Rep 2019; 20(2): 1933-1942.

11. Mairuae N, Cheepsunthorn P, Louicharoen Cheepsunthorn $C$, Tongjaroenbuangam. Okra

(Abelmoschus esculentus Linn) inhibits lipopolysaccharide-induced inflammatory mediators in BV2 microglial cells. Trop J Pharm Res 2017; 16 (6): 1285-1292.

12. Yang $H$, Dong $Y, D u H$, Shi $H$, Peng Y, Li X. Antioxidant compounds from propolis collected in Anhui. China. Molecules 2011; 16(4): 3444-3455.

13. Re R, Pellegrini N, Proteggente A, Pannala A, Yang M, Rice-Evans C. Antioxidant activity applying an improved ABTS radical cation decolorization assay. Free Radic Biol Med 1999; 26(9-10): 1231-1237.

14. Gao HM, Zhou H, Hong JS. Oxidative Stress, Neuroinflammation, and Neurodegeneration Neuroinflammation and neurodegeneration 2014; 81 : 104.

15. Benjawan D, Mark CT, Kanjana $T$, Patcharawan $S$, Tanaporn H, Griangsak E. Intracellular ROS Scavenging and Anti-Inflammatory Activities of Oroxylum indicum Kurz (L.) Extract in LPS plus IFN-y-Activated RAW264.7 Macrophages. Evidence-Based Complementary and Alternative Medicine 2020; 20: 1-15.

16. Sharma JN, Omran AA, Parvathy SS. Role of nitric oxide in inflammatory diseases. Inflammopharmacology 2007; 15(6): 252-259.

17. Wu YY, Hsu JL, Wang HC, Wu SJ, Hong CJ, Cheng IHJ. Alterations of the Neuroinflammatory Markers IL-6 and TRAIL in Alzheimer's Disease. Dement Geriatr Cogn Dis Extra 2015; 5(3): 424-434.

18. Lee JY, Park W. Anti-inflammatory effects of oroxylin A on RAW 264.7 mouse macrophages induced with polyinosinic-polycytidylic acid. Exp Ther Med 2016; 12(1): 151-156. 